\title{
Empirical Study of Hedonic and Utilitarian Attitudes toward Network Consumption
}

\author{
Hailin $\mathrm{Su}$ \\ School of Business \\ Jiaxing University \\ Jiaxing Zhejiang, China \\ Shuimeimumu1982@126.com \\ Fang Fang \\ School of Business \\ Jiaxing University \\ Jiaxing Zhejiang, China \\ fangfang@qq.com
}

\author{
Dake Qian \\ School of Business \\ Jiaxing University \\ Jiaxing Zhejiang, China \\ checkout@163.com
}

\author{
Kai-li Yu \\ College of Food Science and Technology \\ Shanghai Ocean University \\ Shanghai, China \\ 460628160@qq.com
}

\begin{abstract}
Due to the rise of the network society, consumption structure has consequently changed. The network consumption as a new consumption pattern became popular in the world. This paper did a creative research about the impact of hedonic and utilitarian attitudes of the consumer taking the network as consumer environment on spending propensities of consumers. This article, from the perspective of consuming attitudes of consumers, builds both hedonic and utilitarian attitudes of network consumption and tests the effect of these two attitudes on network consumption propensities through empirical research. The study found that hedonic attitude has a prominently positive effect on the network propensity to consume, and utilitarian attitude has a negative but indistinct impact on network consumption.
\end{abstract}

Keywords - Consumption propensities, hedonic, network consumption, utilitarian

\section{INTRODUCTION}

With the rising of the network society with informatization as its typical characteristic, there came some new changes in people's consumption structure, among which network consumption as a new consumption pattern has become popular in the world. The network consumption, broadly speaking, refers to the action of the trading of goods or services through Internet directly or indirectly, and it is a sum of all consumption forms including online shopping, online education, online video, and online games. Just in terms of online shopping, the Chinese Internet survey data shows that by the end of June 2012, online shopping users reached 210 million, which increased 8.2\% compared with the end of 2011. Starting from 2011, the growth of online shopping users has been gradually stable. The future development of online shopping market will not only rely on the growth of user scale but more on the continuous improvement of consumption depth to drive.

In recent years, Chinese people's consumption behaviors began to present the typical characteristics of hedonism or utilitarianism from different levels. Domestic and foreign scholars measure the differences in attitudes of consumers' hedonism and utilitarianism from several aspects such as product brands and product types. This paper did an innovative research about the impact of hedonic and utilitarian attitudes of consumers taking network as a consumer environment on spending propensities of consumers. In the area of electronic commerce, it has become an important means of corporate marketing to market products and services by using online media. This study can help the provider of shopping sites to have a better knowledge of the attitudes and behaviors of online consumers and provide a reference for carrying out network marketing. Then they will be able to develop reasonable strategies about online marketing.

\section{LITERATURE REVIEW}

\section{A. Utilitarian Attribute of Network Consumption}

Network consumption has following several characteristics: various types of products in online stores, no restriction on the area of shops, no time limit, low cost, relatively low prices of online goods, easy search for goods, and a wide range of services of online stores. He Mingsheng (2001) deemed that the resource nature of time in network consumption is very prominent because its potential value continues to improve and is scarce [1]. Traditional consumption is boundary: shopping place is boundary, so is consumption space. Network consumption breaks these physical boundaries, so it is non-border consumption. Meanwhile network consumption also has risks. In network consumption, there are some perceived risks such as credit risk, payment risk, the risk of transfer of goods, as well as the risk of rights and interests of consumers being difficult to maintain. Therefore, utilitarian attribute of the network is bidirectional properties including positive and negative on one dimension. 


\section{B. Hedonic Property of the Network Consumption}

Toffler (1970) proposed the concept of "production consumers". Compared with the traditional material consumption, network consumption is an "indirect" consumption, for it does not consume the network and the information itself, but would like to use the results and functions created by networks, information and other input factors. Network consumption possesses hedonic property and it can bring such fun to consumers as sensory enjoyment, social intercourse, bargaining, and adventure. Holbrook \& Hirschman (1982) put forward that though the information processing model can explain the purchasing behaviors of most customers, those traditional studies have ignored the important aspect of customer experience [2]. It is difficult for the traditional cognition or cognitive model based theory to interpret the following behaviors: leisure activities, aesthetic activities, symbolic consumption, the pursuit of multiple changes, hedonic consumption and entertainment. 2Hoffman and Novak (1996) thought that when browsing the website to interact with the computer, the individual will have the state of the flow experience, forget the passing of time, as if being in the action, and would lose self-perception and develop the feeling of joy [3]. The investigation report on China's Internet hotspots issued by CNNIC showed that $24.9 \%$ respondents went online for shopping out of curiosity [4]. Network consumption can bring to online consumers some hedonic attitudes, for example the joys of social contact, bargaining and adventure.

\section{RESEARCH HYPOTHESIS}

The consumer attitude can be divided into hedonic consumption and utilitarian consumption in the network consumption. The former tends to pursue change, emotional factors and symbolic features; while the latter is more inclined to rationality, pursuing practical features. It is necessary to examine consumer attitude towards network consumption from both hedonic consumption and utilitarian consumption perspective. Network consumers who hold hedonic attitude pay more attention to pleasure, fun, and feeling, and lay stress on enjoying the fun and entertainment, focusing on the process of network consumption as well as the enjoyment and subjective experience in the process; the others who hold utilitarian attitude emphasize the benefits, utility and function brought by network consumption. Network consumption can thus bring the consumers enjoyment and utility, so it is appropriate and meaningful to construct a hedonic dimension and utilitarian dimension of leisure or a casual consumer attitude.

Different consumer behaviors are results from two different consumption attitudes [5]. Hedonic and utilitarian are not two extremes of the scale of a single attitude dimension, because customer attitude towards the network consumption consists of hedonic dimension and utilitarian dimension which both have an effect on customers. Customer attitude contain both hedonic component and utilitarian component. What different is that if there are more hedonic components and less utilitarian components in some customers' attitude, the hedonic attitude plays an main role in the customer behaviors; Otherwise, the utilitarian attitude have larger impact on customer.

This paper argues that the network consumption has hedonic attribute and utilitarian attribute leading to hedonic attitude and utilitarian attitude of online shoppers. According to the TRA theory, attitude will affect consumer behavior. The higher the consumers evaluate the hedonic attitude and the more they focus on the pleasure brought by network consumption, the stronger the tendency of the customer network consumption will be, the higher consumer evaluate utilitarian attitude. Network consumption has positive and negative utilitarian attributes and it's the latter mainly lead the online shoppers. The more consumers focus on utilitarian attribute of network consumption, the more their negative utilitarian attitude will be, as a result the tendency of their network consumption will be weaker. This paper argues that hedonic attitude and utilitarian attitude both have an impact on consumers' propensity to consume, so it proposes the following hypotheses:

H1: The hedonic attitude of network consumption has a positive influence on the intention of network consumption;

$\mathrm{H} 2$ : The utilitarian attitude of network consumption has a negative influence on the intention of network consumption.

\section{EMPIRICAL ANALYSIS}

\section{A. Research Background and Questionnaire Design}

The CNNIC survey released in January 2009 shows that the main force of online shopping are college students and white-collar group with middle income, so the official research time of this study is June and July 2011 and the research objects are college students and company employees [6]. The research takes the questions on hedonic and utilitarian attitude developed by Li Yufeng (2008) on the basis of Voss and other scholars' study. Combined network consumption, this study makes survey with 7 questions on hedonic attitude whose code is HEDO, and 5 questions on utilitarian attitude whose code is UTL. The survey of intention of online shopping adopts the three questions of consumption tendency on leisure consumption developed by Wu Sizong (2010) based on the study of Zeithaml, Berry \& Parasuraman and Grewal, Monroe \& Krishnan [7]. Shopping is also one kind of leisure. This paper proposes three questions to research the intention of online consumption whose code is INTEN: intention of spending money on network consumption, intention of spending time on network consumption and intention of exchanging things about network consumption with others. It uses Likert's 7-point scale.

\section{B. Sample Description}

There are 324 valid questionnaires through the research (399 returned questionnaires, and effective ratio is $81.24 \%$ ). The proportion of males in effective samples of this paper is $59 \%$, females $41 \%$; 25 years old and under age 44\%, 25-30 years old $16 \%, 31-40$ years old $29 \%, 41-50$ years old $8 \%$, over 51 years old $3 \%$; and $89 \%$ of consumers have higher education degrees. 


\section{Analysis of Reliability and Validity}

This study uses software SPSS13.0 and adopts Cronbach's $\alpha$ value to measure the reliability of each variable, taking Cronbach's $\alpha$ value greater than 0.7 as standard [7]. The running results show: the test index of hedonic attitude, utilitarian attitude and intention of networking consumption all are between 0.772 to 0.845 , so we can say the research questions of each variable, to some degree, have internal consistency and stability. The study tests and constructs validity by using exploratory factor analysis. According to the result of SPSS analysis, KMO value is 0.765 in the exploratory factor analysis on hedonic and utilitarian, and the $\mathrm{P}$ value is less than 0.001 tested by using Bartlett's sphericity. We can learn that each variable is fit for factor analysis, so is this dimension. Finally, the result of factor analysis indicates that convergent validity and interval validity of each question is good.

D. Structural Equation Analysis

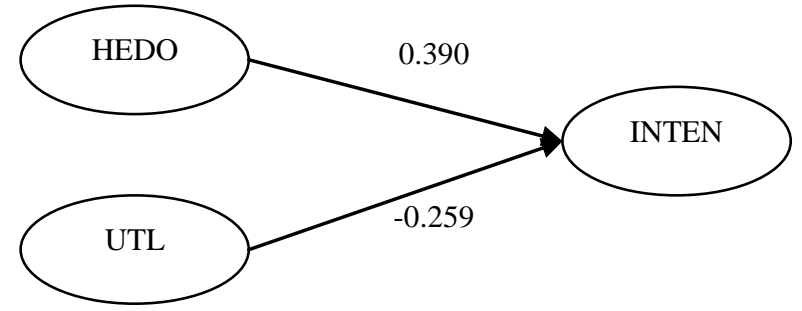

Figure 1. path relationship and path coefficients of the structural model

The hedonic attitude and utilitarian attitude are exogenous latent variables, and propensity to consume online is endogenous latent variable. According to the fitting results by AMOS software on the model in this paper, hedonic attitude of network consumption (HEDO) $\rightarrow$ intention of network consumption (INTEN): the path coefficient is 0.39; utilitarian attitude of network consumption (UTI) $\rightarrow$ intention of network consumption (INTEN): The path coefficient is -0.259 . Each fitting indicator of models mentioned above has reached the standard.

\section{E. . Hypothesis Testing}

The above analysis and test show that the hedonic attitude of network consumption has a positive and remarkable impact on the willingness of network consumption, so research hypothesis $\mathrm{H} 1$ is verified; Research hypothesis H2: the utilitarian attitude of network consumption have a negative impact on the willingness of network consumption, does not get verification, because utilitarian attitude of leisure consumption has a greater effect than the hedonic attitude on the willingness of leisure consumption.

\section{CONCLUSION AND ENLIGHTENMENT}

\section{A. Conclusion}

In summary, we can draw four following conclusions in this paper. 1 has obvious feature of two-dimensional structure of hedonic and utilitarian. Customers treat network consumption for the reason of hedonic and utilitarian. The hedonic attitude of network consumption has a positive and remarkable effect on willingness of network consumer, and the utilitarian attitude of network consumption have a negative impact on 2, but not significantly. The utilitarian attitude of network consumption has a greater effect than the hedonic attitude on the willingness of network consumption. This paper applies the scale improved by $\mathrm{Li}$ Yufeng and $\mathrm{Wu}$ Sizong to test the attitude of the domestic network consumption. The results indicate that the scale worked well in the empirical study, which can do further testing or use in domestic practice.

The hedonic attitude has a great impact on propensity to consume online, which suggests that the consumption value of hedonistic tendency prevails, individual paying more attention to the fun, pleasure, feeling, aesthetic, emotion and other factors in the process of consumption. Websites should immerse consumers by making beautiful pictures, adding relaxing and soothing music, and using emotional appeal of promotion strategy. In this way, it can wake up some kind of emotion, making consumers generate the fun of sensuality enjoy, social contact, bargaining and adventure. Online shoppers will immerse themselves in browsing the online shops as if they are at the scene, forgetting the passing time and feeling happy; they can meet the needs of individual interpersonal communication by virtual interaction with the shop owner in the purchase process; they can experience the fun of seeking discount and privilege by bargaining with the shop owner as possible as they can regardless of losing face owing to anonymousness; additionally, online shopping can meet online shoppers' curiosity about new things, inspiring them to experience the fun of adventure .

The study finds that consumers have both hedonic attitude and utilitarian attitude when they are doing shopping online, but hedonic is the main attitude showed by the research data. Although it is convenient and effective for the consumers to do shopping online, the utilitarian attitude has a negative impact on the propensity to consume online, even the impact is not significant. The results of this study may suggest that customers who hold utilitarian attitude has a lower tendency to chose network consumption and purchase online. The reason for the results of this study may be that though there are many positive utilitarian attributes of network consumption, consumers holding utilitarian attitude do not completely holds them in the network consumption. They are, instead, more sensitive to the negative ones. The existing risk of network consumption has increased consumers' negative utilitarian attitude, which reveals the current situation of China's network consumption that most network consumers hold hedonic attitude. With the development of China's network consumption, consumers' network consumption attitude will be mature gradually; the attitude of the consumer network consumption will continue to mature. As time goes by, consumers' hedonic and utilitarian of network consumption attitude will together affect the propensity to consume online. 


\section{B. Enlightenment}

As for network trust, compared to the hedonistic consumption, consumers actually pay more attention to the utilitarian consumption. The result of consumer research support that it is necessary to improve the network trust. The lack of network trust has become a limited factor for the further development of network consumption. The study on determinants of consumers' network trust and the intention of resulting behavior will have great significance for network enterprises to develop strategies of improving consumers' trust.

As for consumption experience, compared to the utilitarian consumption, the hedonistic consumption provides consumers more multiple feelings as well as relatively more multilateral experience. This study shows that the hedonic attitude of network consumption has a greater effect than the utilitarian attitude on the tendency of network consumption, which contributes to applying flow experience of the positive consumption psychology to the study of network consumption. For now, flow experience is the mainstream research in the field of network consumption experience, but the two-dimension structure of hedonic and utilitarian consumption has strongly supported the application of flow experience in network consumption

This study helps to explain the current trend of online shoppers' addiction, and the reason is too much social pressure and lack of social support system. The tendency of hedonistic consumption value accelerates consumers being close to online shopping. It is consumers obsessed by the process of online shopping emphasizing the hedonic attitude that let individuals be indulge in online shopping and unable to extricate themselves.

\section{REFFERENCES}

[1] Minshen He, Yijun Li. Basic Features of Network Consumption and Its Breaking through in the Traditional Economic Theory. Academic Exchange. 2001(2), 105-108

[2] Holbrook M B, Hirschman E C. The experiential aspects of consumption: Consumer fantasies, feelings, and fun [J]. Journal of Consumer Research, 1982, 9 (2): 132 - 140.

[3] Hoffman, Donna L., \& Novak, Thomas P. Marketing in hypermedia computer-mediated environments: Conceptual foundations [J] Journal of Marketing, 1996, Jul, 60: 50-68.

[4] CNNIC. The Survey of Chinese Internet Netwok Hot topic. [R]. 2004, $10-21$

[5] Spangenberg E R, Voss K E, Crowley A E. Measuring the hedonic and utilitarian Dimensions of attitudes: A generally app licable scale [J]. Advances in Consumer Resear ch, 1997, 24 (1): 235 - 241.

[6] CNNIC. The Survey of Chinese Internet Netwok Hot topic. [R]. 2004, $10-21$

[7] Sizong Wu, Hai Guo. Study on HED/UT Attitude towards Leisure Consumption [J]. Tourism Tribune. 2010, (3): 55-61

[8] Nunnally, J. Psychometric Theory [M]. McGraw, New York, NY, $1979,56-80$ 